\title{
Digital transformation as an interaction-driven perspective between business, society, and technology
}

\author{
Ziboud Van Veldhoven $^{1}$ (D) Jan Vanthienen ${ }^{1}$
}

Received: 18 February 2020 / Accepted: 8 February 2021 / Published online: 10 March 2021

(C) Institute of Applied Informatics at University of Leipzig 2021

\begin{abstract}
Digital transformation, a term introduced to talk about the various changes in business and society due to the increased usage of digital technologies, has recently gained much attention both in research and in practice. However, an analysis of 41 digital transformation frameworks following a developmental literature review shows that several areas can be expanded upon. We propose a novel framework that deals with the underrepresented areas by consolidating the various concepts found in the literature, explicitly including the role of society, highlighting the evolution over time, and including the drivers of digital transformation that we classified into 23 'digital transformation interactions' across six categories. This novel perspective contributes to our macro-understanding of digital transformation and can be used as a lens for further research to generate fresh insights into unanswered research avenues. Ultimately, this paper can be the first step towards a unified understanding of digital transformation.
\end{abstract}

Keywords Digital transformation · Digital innovation · Digitalization · Business transformation · Digital transformation drivers · Framework

JEL classification 0330

\section{Introduction}

The world is changing at a rapid pace. The increasing usage of and reliance on digital technologies brings forward a myriad of major changes in both business and society. To talk about these changes, the concept of digital transformation (DT) was introduced back in the year 2000 (Patel \& McCarthy, 2000). However, it was only after 2014 that the term swiftly grew in popularity both by practitioners and researchers (Reis, Amorim, Melão, \& Matos, 2018). Numerous and diverse definitions have been proposed for DT ranging from "a process that aims to improve an entity by triggering significant changes to its properties through combinations of information, computing, communication, and connectivity technologies" (Vial,

Responsible Editor: Hans-Dieter Zimmermann

Ziboud Van Veldhoven

ziboud.vanveldhoven@kuleuven.be

1 KU Leuven, Research centre for information systems engineering (LIRIS), Naamsestraat 69, 3000 Leuven, Belgium
2019, p.1) to "the changes that the digital technology causes or influences in all aspects of human life" (Stolterman \& Fors, 2004 , p.3). It is worth noting that DT is not an entirely new concept; its roots can be found in digitization, i.e. converting analog data and processes into digital variants (Henriette, Feki, \& Boughzala, 2015), and in digitalization, i.e. the sociotechnical process in which digital technologies are adopted at a large scale (Legner et al., 2017). There is some semantic confusion surrounding these terminologies, but in general, DT is framed as a broader transformation compared to digitalization. Recently, DT has become a major topic in information systems (IS) research and practice with $84 \%$ of global companies regarding DT as critical to their survival in the next 5 years (SAP Center for Business Insight, 2017).

As a result of the academic interest, numerous frameworks of DT have been published to address different needs such as explaining how DT comes about, how DT projects can be implemented, or how a company can assess its DT maturity. A framework, or also called a model, is a visual representation of a phenomenon consisting of its key factors, variables, and the relationships between them. This study set out to critically investigate and compare these frameworks which led to the 
identification of several research opportunities. First, there exists a disparity between the frequently mentioned role of society in the DT literature (e.g. Loebbecke \& Picot, 2015a and b; Matt, Trenz, Cheung, \& Turel, 2019) and its absence in DT frameworks. Secondly, most frameworks focus on a certain technology, change, or timespan. A holistic framework that reconciles the entire evolution over time lacks (Henriette et al., 2015). Likewise, we found many drivers or enablers of DT in the literature. Yet only a handful are present in the reviewed frameworks. And despite prior work in conceptual frameworks, there still exists a lack of understanding surrounding the phenomenon (Vial, 2019) and its terminology (Goerzig \& Bauernhansl, 2018; Haffke, Kalgovas, \& Benlian, 2016; Mertens \& Wiener, 2018).

There is a growing body of research that recognizes and investigates these problems (Nwaiwu, 2018; Vial, 2019). However, the goal of this paper is to take another position on the matter by introducing a conceptual macro-framework that expands upon the four identified research opportunities. The framework, of which a preliminary version was introduced in previous work (Van Veldhoven \& Vanthienen, 2019), is based on the consolidated insights from the DT literature and the analysis of 41 DT frameworks stemming from a developmental literature review. This literature review is described in the next section. In the third section, we go deeper into the identified research gaps after which we propose our framework that highlights the highly interactive nature between changes in business, society, and digital technologies in section four. Based on the framework, we open a discussion on the current and future research on DT and propose a research agenda in section five.

\section{Background and related work}

We conducted a development review of the literature (Templier \& Paré, 2015) to find papers that offer a framework of DT. For the inclusion criteria, we consider papers termed with DT and dealing with the transformation happening in business or society due to digital technologies. Hence, we do not include papers dealing with isolated projects or the implementation of a certain technology such as data mining applications. Frameworks that discuss or explain one or more aspects of DT are included in the analysis. Both Scopus and Web of Science were searched with the query 'digital transformation AND (model OR framework)' in the title, abstract, or keywords. Different queries were assessed but resulted in either too many false positives or too many papers to analyze for the scope of this paper. We limited our initial search to cited $(>5)$ conference and journal papers in the last 10 years in the fields of business, management, economics, and social sciences. Next, we extended our search with backward and forwarding referencing to include the frameworks that were used as a basis for or that were built upon the initial set in this study (Webster \& Watson, 2002). This way, we indirectly include frameworks linked with for example digitalization. In total, more than 250 papers were reviewed which resulted in the analysis of 41 frameworks that forms the basis of our problem statements and the building blocks of our design. In general, three types of frameworks can be identified: conceptual, transformation, and maturity frameworks.

\section{Conceptual frameworks}

Conceptual frameworks describe the phenomenon of DT in a general way to help people better understand or simulate the matter. Several authors represent DT on a semi-abstract level as the iterative process between digital innovations, their implementation or diffusion at the firm level, and their impact without going into specifics (Faro, Abedin, \& Kozanoglu, 2019; Skog, Wimelius, \& Sandberg, 2018). Similarly, but on a firm-level, DT is sometimes represented as distinct, iterative phases such as evaluating the current value creation, assessing the organization's digital capabilities, and providing value equations for each digital capability (Rautenbach, Kock, \& Jooste, 2019). A more detailed framework is given by Vial (2019) that describes how digital technologies fuel digital disruptions such as changes in the competitive landscape. This causes strategic responses from companies that change the value creation paths and affect the organization's structure, culture, and leadership. In a similar vein, Mergel, Edelmann, and Haug (2019) and Schallmo and Williams (2018) structure DT around what business aspects are changed, the typical processes through which this happens, and the output. While Mergel et al. (2019) include the reasons for DT as both external pressure from the environment and internal pressure, Schallmo and Williams (2018) focus on the goals of DT such as cost savings and better quality. Matt, Hess, and Benlian (2015) take a more general, strategic perspective, stating that DT is about aligning technologies, changes in the value creation, structural changes, and the financial aspects. A practical and more exhaustive approach is followed by Kotarba (2018) who adapts the business model canvas (Osterwalder \& Pigneur, 2010) with the common digital solutions and technologies since 1980 such as microservices and web-portals. This way the framework can be used as a tool for businesses to simulate potential disruptions, changes, or DT projects. Similar but more general ones are proposed by Pihir, Tomičić-Pupek, and Tomičić Furjan (2019). Finally, a hybrid framework (both iterative and relatively exhaustive) described DT as the interplay between the business, managerial choices, resources, and the competitive landscape (Sanchez, 2017). While these models explain what DT is, they do not offer any advice on how a company should initialize DT projects. 


\section{Transformation frameworks}

Transformation frameworks describe how DT projects are typically carried out or should be implemented in companies. They can be used as tools for managers guiding DT projects, but they often lack specific details on how a company can perform each step. There is a common consensus on the general steps of how a DT project must be carried out: initiation, ideation, assessment, commitment, implementation, and sustainability (Kaufman \& Horton, 2014; Schallmo, Williams, \& Boardman, 2017; von Leipzig et al., 2017; Ziyadin, Suieubayeva, \& Utegenova, 2020), following a similar pattern as in business transformation models (e.g. Kotter, 1995). Similarly, Westerman, Calméjane, Bonnet, Ferraris, and McAfee (2011) describe three steps. First, a company must envision its digital future. Secondly, more investments in line with the vision need to be done in people, equipment, initiatives, and technology. Lastly, the needed transformation needs to be led from the top. Likewise, Parviainen, Tihinen, Kääriäinen, and Teppola (2017) state that a company must first review its current state, then identify the alternative scenarios and use that to sketch a roadmap, and lastly implement the needed changes and validate with the goals of the project. A different approach is taken by Berman (2012) who observes three common paths to implement change: redefining the customer experience, reshaping the operational model, or both.

\section{Maturity frameworks}

Maturity frameworks describe the different states of DT maturity in organizations. They can be valuable to assess a company's maturity, strengths, and weaknesses, or as a comparison tool between competitors. Although they often lack guidance as to how a company can mature. On the one hand, some frameworks explain the distinct phases a company goes through. These are often based on earlier work from Venkatraman (1994) who described five stages of ITenabled transformation: localized exploitation in which standard tasks are digitized without changing the business process itself, internal integration between the different IT solutions, redesigning the business processes to fully leverage the IT potential, redesigning the business network, and redefining the business scope or model. For example, Morgan and Page (2008) mention four phases: automation of selected activities, creating ICT synergies, redesigning the business network, and reframing the entire business model; Matzler, Friedrich von den Eichen, Anschober, and Kohler (2018) mention 3 stages: digital products, digital decisions and processes, and digital business models; and Issa, Hatiboglu, Bildstein, and Bauernhansl (2018) adapted a maturity framework for industry 4.0 consisting of 4 stages: ad-hoc business, isolated silos, cross-departmental integration, and cross-value chain partner integration. On the other hand, there are dimension-based maturity frameworks such as those introduced by ValdezDe-Leon (2016), Gurbaxani and Dunkle (2019), Colli et al. (2018), and Berghaus and Back (2016). In this perspective, the business is divided into generally agreed upon dimensions (e.g. strategy, customer, operations, collaboration, culture, etc.) that each has several stages of maturity (e.g. initiation, enabling, integration, optimizing, and pioneering). A digitally mature company must score well in each dimension. A different perspective is taken by Westerman et al. (2011) who created four levels of digital maturity based on the digital intensity of IT capabilities and the transformation management intensity of DT leadership. A more specific approach can be found in the works of Ifenthaler and Egloffstein (2020) who list the indicators for digital maturity per business dimension in educational organizations such as the presence of certain technologies.

\section{The need for a novel framework}

By analyzing the DT literature and the retrieved frameworks, we believe that there is room for a conceptual framework that expands upon four identified white spots. First, there exists a disparity between the frequently mentioned role of society in the DT literature (e.g., Matt, Trenz, Cheung, \& Turel, 2019; Misuraca, Pasi, \& Viscusi, 2018) and its lack in DT frameworks. In the analyzed frameworks, DT is often explained as a response to novel digital technologies. Yet, it can also be considered as a response to changes in society (Nwaiwu, 2018). It are, for instance, the digitalized society and the empowerment of customers that create a myriad of new business possibilities that are now driving DT (e.g. in the sharing economy). The role and impact of a changing society are receiving growing attention in research but are not yet included as a key component in the analyzed frameworks. Including this entity and its influence in a conceptual framework can be important to get a better understanding of the bigger picture (Matt et al., 2019).

Secondly, most frameworks are specific by focusing on certain business changes or the implementation of certain technologies in organizations. This way, many components are linked with DT but no framework integrates them all. Many others are abstract and iterative; they do not specify the technologies or changes themselves but refer to the continuous change process and implementation of the current novel technologies. Although iterative frameworks are a good fit since it is generally agreed that DT is a continuous process (Gerbert, Gauger, \& Steinhäuser, 2015; Parviainen et al., 2017; Warner \& Wäger, 2019), a more detailed formalization of the technologies and changes can be beneficial to better understand what is happening. On the other hand, digital technologies change so fast that it is hard to pinpoint DT on 
specific technologies (Riasanow, Setzke, \& Böhm, 2019). Hence, a trade-off must be made between simplicity and completeness. A robust macro-framework is needed that summarizes the phenomenon, including its evolution and key components, and leaves room for future expansion (Henriette et al., 2015).

A third area that can be expanded upon is the inclusion of the drivers or enablers of DT. In the reviewed frameworks, the mentioned drivers consist mostly of novel technologies or the changing environment. Nevertheless, many more drivers are found to play a substantial role in DT such as the internal pressure from employees (Kane, Palmer, Phillips, Kiron, \& Buckley, 2017; Westerman et al., 2011), or the network effects that decide what technologies companies must follow. In addition, most authors agree that the pace at which the changes are happening is increasing (Catlin, Scanlan, \& Willmott, 2015) but limited work has been conducted to understand why. Understanding and investigating the driving forces behind DT is of fundamental importance in studying how the changes unfold. Therefore, a DT framework with a larger focus on the drivers should be a welcome addition to the IS research field.

Last, more effort is needed to consolidate the many concepts and terminologies that have been linked to DT. Despite the numerous frameworks that seek clarification, many 'synonymous' terms of DT, such as digitalization and ITenabled transformation, can be found in the literature without a clear agreement on their exact meaning, scope, and relationship (Kane et al., 2017a and b; Riasanow et al., 2019). Besides, DT itself has numerous and diverse definitions. This ambiguity causes the disputed expansion of the research field and the term's expressive power to fade. Limited work has been conducted in these frameworks to describe the relationship between these terms. A conceptual framework that clearly outlines the meaning of DT, its evolution, and its related terms can be beneficial to advance the research field.

\section{The proposed interaction-based DT framework}

To solve the challenges stated in the previous section, this work endeavors to consolidate the common concepts and building blocks that emerged through our analysis of the DT frameworks and literature into a holistic framework. While most reviewed frameworks are focused on the entities business and technology, we propose a broader one that also includes society. As such, the framework contains three axes to represent the main entities: digital technologies, business, and society. For each entity, we summarized its main developments regarding DT in five categories which ensures both simplicity and completeness. Rather than restricting the axes to these five categories, we highlight the continuous evolution by making boundless axes. We also included 23 drivers of DT, represented by the circular arrows between the axes, and categorized them based on the location in the framework.

\section{The three axes: Changes in digital technologies, business, and society}

Under the digital technologies' axis, we understand the major digital technology developments that have steered the transformation over time, which can be summarized in five waves based on the historical evolution and the insights from the framework analysis. The first wave started in the 70 s with initial $I T$ solutions for the automation of simple tasks using computer technology (Legner et al., 2017; Venkatraman, 1994). Later, internet or ICT solutions for faster information sharing and connectivity become prevalent (Heavin \& Power, 2018; Legner et al., 2017). With the massive rise in popularity of digitalized tasks and the internet, more integration solutions arrived such as applications to connect a large amount of data, users, and computers in smart software solutions (Heavin \& Power, 2018). The fourth and current wave, as portrayed by most models, entails the massive rise in social media, mobiles, analytics, cloud computing, and the Internet of Things (SMACIT) (Chanias, 2017; Legner et al., 2017; Vial, 2019). In the next wave, we included emerging technologies which business potentials are not yet fully exploited such as blockchain (and smart contracts), robotics (including 3D printing), artificial intelligence (AI), and cognitive and quantum computing (BRAICQ) (Schwab, 2015; Verhoef et al., 2019). These five umbrella categories capture the most important digital technologies that play a vital role in the DT.

The business axis represents the common, major changes happening over time in organizations, companies, industries, and sectors due to the increased influence of digital technologies and the digitalized society. We base ourselves on the perceived evolution and commonality of the reviewed maturity frameworks to bring these changes under five categories. First, organizations started to digitize or automate internal business processes and isolated activities (Venkatraman, 1994). After that, the connectivity between different business processes, suppliers, systems, or customers got transformed from manual and physical to digital (Morgan \& Page, 2008). The next transformation took place in the offering of the business. Products and services were digitalized and integrated to follow the rapidly changing needs and demands (Hartl \& Hess, 2017; Henriette et al., 2015; von Leipzig et al., 2017). The increased velocity of digital innovation that became apparent at this point, encouraged companies to start changing their organizational structure to be more agile and innovative to respond quickly to changes in the market (Kaufman \& Horton, 2014; Vial, 2019). Lastly, as the rules of the business game got changed, businesses increasingly rework their 
business model (Berghaus \& Back, 2016; von Leipzig et al., 2017). Changes in the business model include focusing on eco-systems (and industry borders fading) (Subramaniam, Iyer, \& Venkatraman, 2019), creating new strategic alliances (He, Meadows, Angwin, Gomes, \& Child, 2020), moving from products to services (Frank, Mendes, Ayala, \& Ghezzi, 2019), ceasing physical fronts, and so forth.

The society axis is focused on the human side of change. Here, we list the major changes happening to people, customers, employees, cities, and governments due to the increased influence of digital technologies and digitalized businesses. These categories are based on a combination of insights from the literature and drawing parallel with the business maturity frameworks. First, the daily tasks people perform in their private lives and at their jobs, in line with the business transformation, have changed considerably compared to the pre-digital era (Reddy \& Reinartz, 2017). Secondly, communication has changed significantly. Not only the medium but the speed and ubiquitous reach have had a drastic impact on the world. Next, the usage of services and products is shifting tremendously and is becoming increasingly digital. All of this is changing the possibilities of how to structure our society (Reddy \& Reinartz, 2017). For example, working and fulfilling basic services can be done increasingly from home. Finally, the profound effects of DT can influence people's values, beliefs, expectations, privacy, and ideologies (Reddy \& Reinartz, 2017; Schwab, 2015). The DT framework is shown in Fig. 1.

\section{The digital transformation interactions}

The five categories within each dimension describe the changes that are happening but do not clarify why this process is occurring. In what follows, we present the frequently mentioned DT drivers and enablers found in the DT literature and frameworks. We call these the DT interactions (DTI) and demonstrate how these fit into our framework. The DTI can be understood as the effects a change in one entity has on the others as well as on itself in a reciprocal way, represented with the circular arrows between the axes in the framework as seen in Fig. 2. These effects happen between business, society, and technology at all stages and in both directions. For instance, the DT of business is influenced by both the changes in society and digital technologies, i.e. the DTI of business.

\section{The DTI of digital technologies}

The DTI of digital technologies describe the influences of business and society that steer the innovation of digital technologies. From the business side, companies can create demand or invest in R\&D for digital innovation. Indeed, many businesses seek to optimize their workflow with digital technologies and are willing to pay for such solutions. This creates the design space; an area with funding or sufficient importance where digital innovation can happen. As such, technology is partly driven by the purpose to reshape the business (Solis, 2015). Another DTI of technology is that businesses have legacy systems in place or are heavily invested in certain technologies. As a result, novel technologies must be compatible or must add value on top of the existing technologies (Baden-Fuller \& Haefliger, 2013). Furthermore, businesses can steer the diffusion of technology thanks to their purchasing and market power, thereby influencing technology standards and adoption.

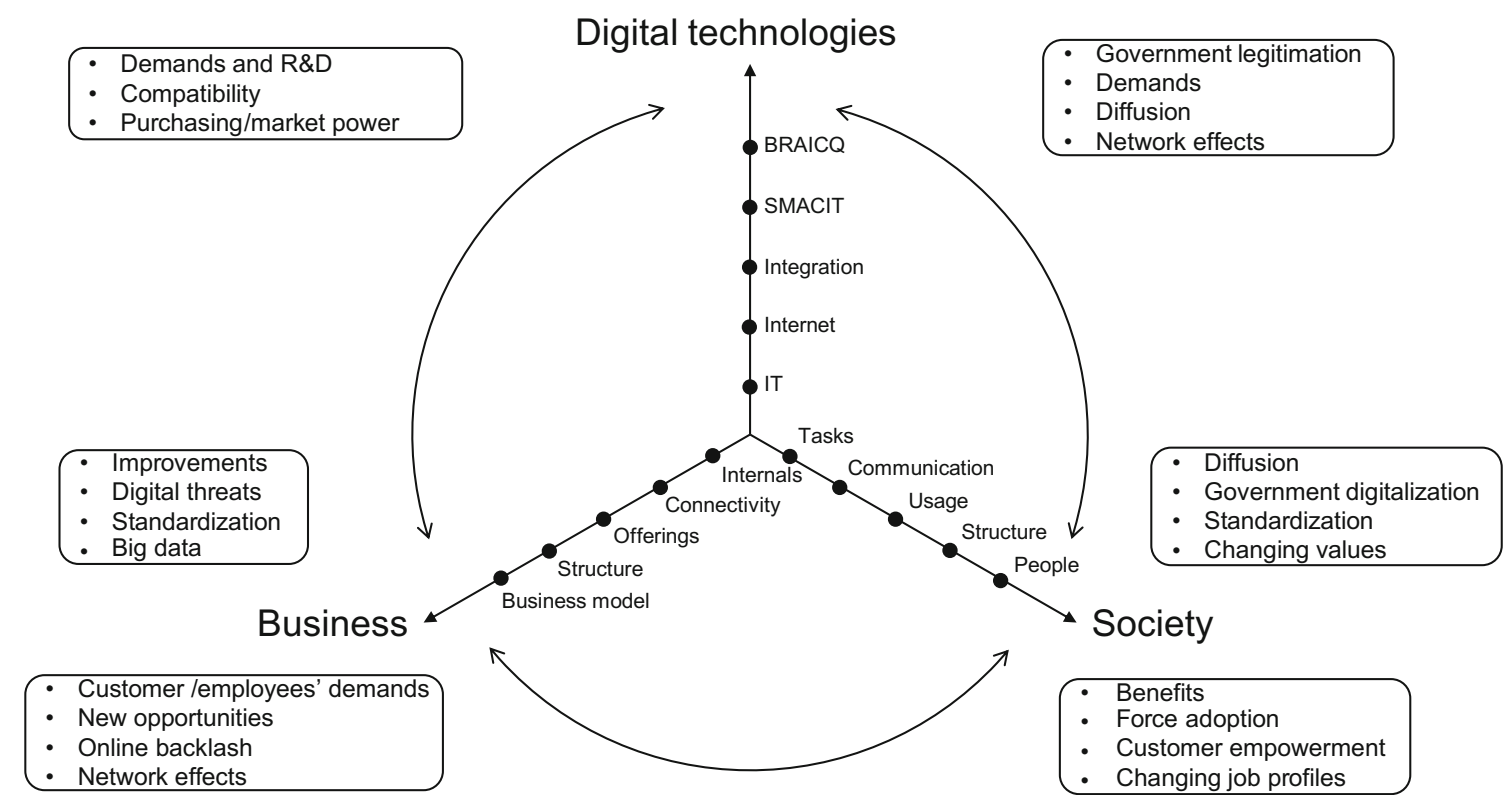

Fig. 1 The interaction-based digital transformation framework 


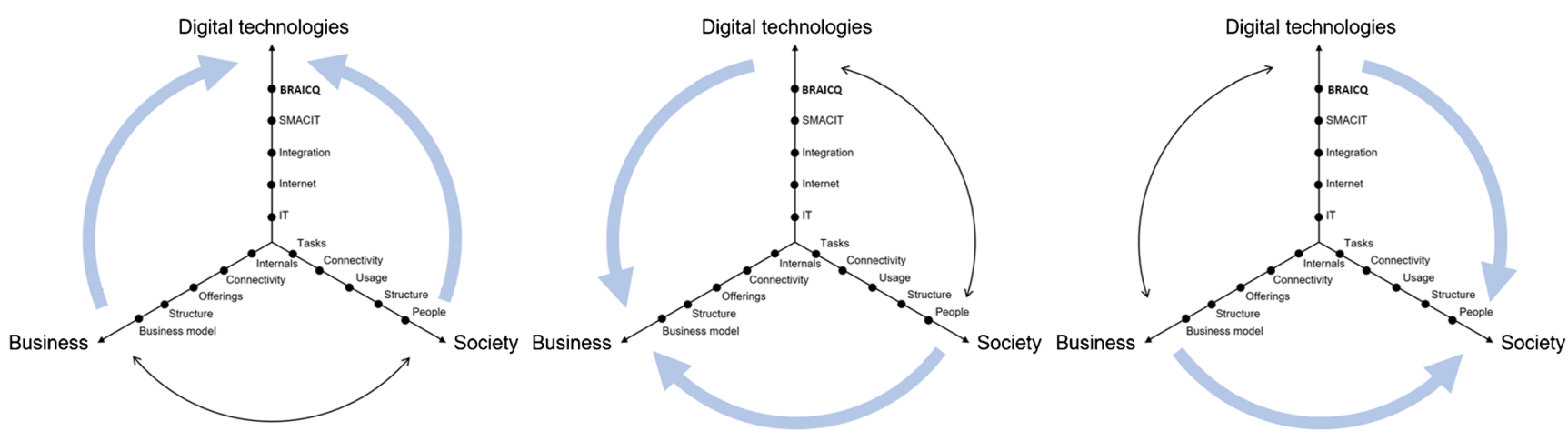

The DTI of digital technologies

The DTI of business

The DTI of society

Fig. 2 The DTI visualized as the circular arrows between business, society, and digital technologies

Society also influences the evolution of digital technologies. The government can play a significant role in digital innovation by deciding what practice is appropriate for digital disruptors, the time lag between innovation and policy legitimation, and can influence the standard-setting through its purchasing power (Hinings, Gegenhuber, \& Greenwood, 2018). In a similar fashion to how businesses demand technology solutions, consumers do too. These demands, which are changing rapidly (Baden-Fuller \& Haefliger, 2013; Risselada, Verhoef, \& Bijmolt, 2013), shape the design space in which digital innovation can happen. Additionally, the diffusion of consumer technology, i.e. the rate at which innovation spreads, is generally decided by consumers' perceived benefits of that technology (Hall \& Khan, 2003). In detail, the technology's perceived advantage, compatibility, complexity, trialability, and observability determine the success rate of high adoption rates (Rogers, 2010). Correspondingly, the adoption levels in society determine the network effects of a certain technology which are a key factor in determining the outcome of technology diffusion. An overview of the DTI of digital technologies is shown in Table 1.

\section{The DTI of business}

The DTI of business describe the drivers from digital technologies and society that pressure the business into DT. The evolution in digital technologies impacts businesses in several ways at an increasingly rapid pace (Brock \& von Wangenheim, 2019). First, there is an incentive for improvements and cost-efficiency by adopting the latest technologies. In recent years, digital technologies have become the main driver of business improvements in the internal processes, communication, products and services, and the business model. Because the rate of digital innovation is increasing, companies must also change their organizational structure to be more agile to continually adapt to these innovations faster (Kane, Palmer, Philips, Kiron, \& Buckley, 2015). An agile organizational structure can be a key differentiator for future DT success (Christensen, Raynor, \& McDonald, 2015). This way, digital innovation has a wide impact on organizations.

There is an important note here. Not only is there the incentive of improvements but also the risk of a competitor gaining a competitive edge by adopting such technologies (Bharadwaj, 2000; von Leipzig et al., 2017). In other words, even if the company does not need to seize the possible improvements, the threat of a competitor doing so and thus offering better service or cheaper products puts the business at risk. Furthermore, the cost of entry in many sectors is lowered, making it easier for digital startups to challenge established businesses (Reddy \& Reinartz, 2017). This vulnerability has also been referred to as digital Darwinism, i.e. only the most innovative businesses survive (Schwartz, 2001; Solis, 2015). As a result, companies must follow digital trends.

Novel technologies can also impact the status quo through standardization pressure. If a large part of the business sector adopts a certain technology, the company feels obliged to follow along. For example, the Automotive Network eXchange Network introduced by a joint venture of General Motors, Ford, and Daimler-Crysler aimed to standardize and automate the interactions with the entire supply chain. The participants of this supply chain were forced to upgrade their IT to be compatible (Andal-ancion, Cartwright, \& Yip, 2003). Similarly, technology standardization in sectors that are not connected to the business can influence the usage of current and future technology solutions. For example, Slack can replace companies' communication solutions when it becomes the standard in many other sectors.

The technological revolution generates a vast amount of data, also known as big data, which provides novel business opportunities. Once more, companies have the choice to do something with this data or risk falling behind when competitors start exploiting it. Hence, many companies start testing the possibilities with analytics, machine learning, and AI (Vial, 2019). To harvest the power of big data, companies 
Table 1 An overview of the DTI of digital technologies

\begin{tabular}{|c|c|c|}
\hline & DTI & Explanation \\
\hline \multirow[t]{3}{*}{ Business } & Demands and R\&D & $\begin{array}{l}\text { Businesses create demand, or invest in } \mathrm{R} \& \mathrm{D} \text {, for technologies } \\
\text { that can improve their operations. In turn, this shapes or funds } \\
\text { the design space for digital innovation. } \\
\text { Example: Business demands drive technologies that can be used for } \\
\text { improving manufacturing such as robotics. }\end{array}$ \\
\hline & Compatibility & $\begin{array}{l}\text { Novel technologies must be compatible with mainstream and legacy } \\
\text { technologies that are present in businesses. } \\
\text { Example: Software innovation is often hindered because it must be backward } \\
\text { compatible with older hardware and software. }\end{array}$ \\
\hline & Purchasing and market power & $\begin{array}{l}\text { The purchasing and market power of companies can partially steer the } \\
\text { diffusion of technology. } \\
\text { Example: Apple can steer the wireless earbuds adoption by removing the audio } \\
\text { jack from their products. }\end{array}$ \\
\hline \multirow[t]{4}{*}{ Society } & Government legitimation & $\begin{array}{l}\text { Governments decide the boundaries of the digital innovation design space with } \\
\text { laws, regulations, and requirements. } \\
\text { Example: The business possibilities of facial recognition, and thus its development, } \\
\text { will be largely dependent on local legislation. }\end{array}$ \\
\hline & Demands & $\begin{array}{l}\text { Customers' demands shape the design space for digital innovation. } \\
\text { Example: Customers increasingly demand safer technologies regarding data management. }\end{array}$ \\
\hline & Diffusion & $\begin{array}{l}\text { The diffusion of technology is partially determined by the technology's perceived } \\
\text { advantage, compatibility, complexity, trialability, and observability. } \\
\text { Example: Many innovative technologies fail due to the lack of adoption such } \\
\text { as mobile virtual reality. }\end{array}$ \\
\hline & Network effects & $\begin{array}{l}\text { The network effects partially determine the diffusion of technology, which can } \\
\text { create standards and lock-ins. } \\
\text { Example: In the US, in contrast to other countries, instant messaging solutions } \\
\text { (such as WhatsApp or Telegram) are less popular due to relatively expensive } \\
\text { mobile data plans, less need for international texting, and the network effects } \\
\text { of SMS and iMessage (e.g. Shwayder, 2019). }\end{array}$ \\
\hline
\end{tabular}

must also restructure their data and IT architecture (Lismont, Vanthienen, Baesens, \& Lemahieu, 2017), and hire employees with the right skillset. Therefore, the generation of big data causes multiple changes in companies.

From the side of society, changing customer demands drive businesses to listen and adapt continually (Rachinger, Rauter, Müller, Vorraber, \& Schirgi, 2018). As the customer demands change, the existing rules of the game within the organization are threatened (Hinings et al., 2018). These demands are shaped increasingly by the digital needs of the customer (Horlach, Drews, \& Schirmer, 2016). Customers also hold increasingly higher standards and are less forgiving to companies' mistakes (von Leipzig et al., 2017). Consequently, one of the most common business guidelines for DT is to be customer-focused.

Additionally, digitalized customers offer a myriad of opportunities for innovative business models (Henriette et al., 2015). Business models of eBay or Lime rely on the fact that a substantial number of customers have access to the internet and smartphones respectively. Similarly, business models that revolve around community collaboration such as YouTube are only possible because of a digitalized society (Berman, 2012). Additionally, research points towards the importance for companies to effectively engage with their digital customer base (Schuchmann \& Seufert, 2015; Solis, 2015). This requires new digital skills and job profiles such as social media managers. Digitalized customers also generate risks. For example, the popularity of dating apps caused many gay bars to go bankrupt. Hence, the digitalized customer base provides both opportunities and threats that companies must account for.

Third, not only customers' but also employees' demands are increasingly putting businesses under pressure to digitalize. On the one hand, it has been shown that employees prefer to work in a company that has an innovative culture and continuous training possibilities (Kane, Palmer, Phillips, \& Kiron, 2017). Furthermore, Solis (2015) notes that some employees have the feeling that coming to work felt like taking a step back in time. On the other hand, changing the company is not easy because many employees oppose novel technologies out of fear of job loss or replacement (Kumar Basu, 2015). Therefore, managing the employees' demands and resistance to change is a struggle many companies must deal with during their transformation (Besson \& Rowe, 2012). This, in turn, is important for creating the right culture inside companies (Hartl \& Hess, 2017). 
In an era of social media, the possibility of online critique or backlash is increasing. Customers want businesses to care about society and the environment, and social media makes it easier to detect, share, and punish companies if they do not (Kaufman \& Horton, 2014). For example, the recent controversy around Blizzard after they declined the prize money earned by a gamer that openly defended the Hong Kong protests of 2019 was ignited and powered by Twitter and Reddit. The company received a massive social backlash: gamers called to uninstall blizzard games and boycott the company, their games received countless bad reviews, and their shares dropped significantly. Another example is online reviews which increasingly determine customer's purchase behavior (Fagerstrom, Ghinea, \& Sydnes, 2010). These examples demonstrate that companies must always be alert of potential online criticism, promote ethics and honesty, and rethink their online presence.

Finally, the network effects in society influence businesses to change. For instance, the popularity of the current popular social media determines the companies' marketing and communication channels. These change rapidly so the company must be ready to switch to new channels. For instance, in just one-year TikTok became the dominant social media app for many teenagers and young adults. Furthermore, the available e-commerce platforms can determine the sales channels, and popular hardware can influence software development (Legner et al., 2017). As a company, it is important to sense these changes and adapt quickly. A summary of the DTI of business is shown in Table 2 .

\section{The DTI of society}

The DTI of society describe why society is changing drastically due to the profound impact of digital technologies and digitalized businesses (Goerzig \& Bauernhansl, 2018; Heavin \& Power, 2018; Matt et al., 2019; Stolterman \& Fors, 2004). Digital technologies influence society in several ways. First, the adoption of digital technologies is determined by their diffusion rate, and thus by the perceived benefit of society (Rogers, 2010). If the perceived benefits are abundant, and they probably are, then society quickly adopts novel technologies leading to DT. Similarly, policymakers are keen on digital technologies to improve several areas in which governments struggle. Public services can be automated to reduce costs. Other examples include the use of facial recognition for better public control and protection (Schwab, 2015), or the use of digital technologies to provide more transparency in all economic activity and thereby reducing the shadow sector of the economy (Ulez'ko, Demidov, \& Tolstykh, 2019). In turn, this leads to more civilians using digital public services.

Technology standards, compatibility requirements, and network effects can also force societies to adopt digital technologies. For instance, when the internet became globally accessible, people were racing to get internet access out of fear of missing out. Another example is the new text message standard called rich communication services (RCS) which is rolling out throughout the world. Countries that do not adopt RCS can run into compatibility issues when communicating internationally, putting pressure on the standardization of network communications. When certain usage thresholds are reached, the technology is pushed to further levels of adoption following the network effects.

Lastly, digital technologies can change people's values, expectations, and demands which in turn leads to more digital diffusion (Matt et al., 2019). Due to the internet, customers are more informed than ever when making purchases or services. And with the help of social media and online communication, they gain the capability to generate controversies instantly when their purchase does not meet demands (Austin \& Upton, 2016; Oestreicher-Singer \& Zalmanson, 2013; Schwab, 2015). Consumers are also given more empowerment when interacting with companies; being able to do things that would previously require interaction with an employee. Furthermore, people get used to the simplicity and speed of digital technologies. For instance, $72 \%$ of customers now expect a response to their complaints on social media within one hour (KPMG International, 2016). All of these developments are part of the reason why people's values and expectations are changing (Lucas, Agarwal, Clemons, El Sawy, \& Weber, 2013). In turn, the increasing demands accelerate the DT of business.

Business can influence the digitalization of society too. By offering more services, convenience, and benefits to their digital customers, customers are encouraged to adopt digital services. For example, many transport companies offer small discounts for ordering tickets with their app versus ordering from the vending machine. In turn, this puts more pressure on the companies that do not yet offer this service. Sometimes, the old services are completely abandoned, and customers are forced to use the new digital solutions.

Secondly, many DT efforts of companies are focused on improving the customer experience (Ivanov, 2019; von Leipzig et al., 2017). As a result, the customer experience is constantly changing and hereby empowering the customer (Kaufman \& Horton, 2014). People are no longer the audience but become part of the product. Customers are becoming digital ambassadors; they can more easily engage with the company, review new features, and share their opinions. In other cases, customers are empowered as cocreators or as community members of the company. Gray et al. (2013) call this center-edge DT in which companies digitally activate the customers to create an ecosystem of digitally connected consumers that can have strategic value. In center-edge DT, consumers interact directly with the company and the customer self-service is extended to offload the workload. 
Table 2 An overview of the DTI of business

\begin{tabular}{|c|c|c|}
\hline & DTI & Explanation \\
\hline \multirow[t]{4}{*}{ Technology } & Improvements & $\begin{array}{l}\text { Adopting the latest technology can offer significant business improvements. Businesses are incentivized to } \\
\text { seize these opportunities, resulting in their increasing digitalization. } \\
\text { Example: The existence of automated manufacturing in one sector can drive automation in other sectors. }\end{array}$ \\
\hline & Digital threats & $\begin{array}{l}\text { Competitors can adopt modern technologies, potentially increasing their competitive edge. As a result, } \\
\text { businesses must become hyperaware of their surroundings and react in time to digital threats. } \\
\text { Example: Blockbuster was too late adopting digital channels for offering its content, allowing Netflix to grow } \\
\text { which eventually drove Blockbuster out of the market. }\end{array}$ \\
\hline & Standardization & $\begin{array}{l}\text { Technology standards can drive companies to follow along. } \\
\text { Example: Enterprise resource planning (ERP) software adoption by one actor in the value chain can require } \\
\text { other actors in the value chain to digitalize their processes and logistics using the same software. }\end{array}$ \\
\hline & Big data & $\begin{array}{l}\text { Digital technologies generate a massive amount of data that can be exploited for novel insights and } \\
\text { improvements. } \\
\text { Example: Companies are acquiring new skills and changing their data management } \\
\text { and structure to create value from big data. }\end{array}$ \\
\hline \multirow[t]{5}{*}{ Society } & Customers' demands & $\begin{array}{l}\text { Businesses must listen and follow rapidly changing customers' demands. Customers are increasingly } \\
\text { demanding, and less forgiving. } \\
\text { Example: Increasing customers' demands require companies to become more responsive and deliver } \\
\text { solutions faster. }\end{array}$ \\
\hline & New opportunities & $\begin{array}{l}\text { Digitalized customers offer opportunities for novel business models by exploiting their hyper-connectivity, } \\
\text { and community co-creation potentials. } \\
\text { Example: Shared mobility solutions are possible thanks to customers having smartphones with a GPS, } \\
\text { constant internet connection, and a camera. }\end{array}$ \\
\hline & Employees' demands & $\begin{array}{l}\text { Employees increasingly demand to work in an innovative and digitalized company. Yet, many employees also } \\
\text { oppose DT out of fear of job loss or replacement. Managing this is an important tussle during DT efforts. } \\
\text { Example: McDonald's introduced touchscreens to order food, replacing manual labor. Instead of firing } \\
\text { employees, the company used the newly available capability to bring food to the customers' table. }\end{array}$ \\
\hline & Online backlash & $\begin{array}{l}\text { Social media can create an unseen social backlash. Companies must be alert of potential online criticism and } \\
\text { promote ethics and honesty throughout the company, hereby rethinking their online presence. } \\
\text { Example: Blizzard received major online backlash after declining prize money to a gamer that openly } \\
\text { supported the Hong Kong protests of } 2019 \text {. }\end{array}$ \\
\hline & Network effects & $\begin{array}{l}\text { Network effects can determine the marketing, communication, and sales channels. Additionally, hardware } \\
\text { popularity influences software development. } \\
\text { Example: New social media launches frequently, changing the usage shares of targeted customer segments. } \\
\text { For example, we saw the massive rise of TikTok in the past year. Companies must always evaluate their } \\
\text { marketing channels accordingly. }\end{array}$ \\
\hline
\end{tabular}

Another reason for the DT of society is that jobs are evolving in line with the DT of the businesses (Henriette et al., 2015). There are many changes in existing jobs as well as the emergence of new types of jobs (Schwarzmüller, Brosi, Duman, \& Welpe, 2018). In existing jobs, digital skills become more important which leads to large skill gaps in the job market (Westerman, Bonnet, \& McAfee, 2012). Also, the emergence of new job roles makes it difficult for education and training to properly prepare the workforce (World Economic Forum, 2018). There is also a fear of massive job loss because machines can replace a rising number of tasks and jobs due to robotics and AI (Guest, 2014; Loebbecke \& Picot, 2015b; Ulez'ko et al., 2019). As a result, employees are becoming increasingly trained in digital skills. A summary is shown in Table 3 .

\section{Discussion}

The comprehensive framework put forward in this paper expands upon the four identified research potentials. First, we widen the research field by explicitly considering society, highlighting its significant role in DT. This is important because DT cannot be looked at solely from a business and technology perspective (Schallmo \& Williams, 2018; Ulez'ko et al., 2019). Consequently, we call for more transdisciplinary research in social sciences and IS (Legner et al., 2017). We believe that DT has both the expressiveness power and academic attention to bring together these research streams to improve our understanding of DT and to better investigate the role of society in this phenomenon. Secondly, this paper contributes to our macro-understanding of DT by summarizing the 
Table 3 An overview of the DTI of society

\begin{tabular}{|c|c|c|}
\hline & DTI & Explanation \\
\hline \multirow[t]{4}{*}{ Technology } & Diffusion & $\begin{array}{l}\text { People adopt digital technologies due to their perceived benefit in their personal lives or due to necessity. } \\
\text { Example: A smartphone quickly became a necessity for many jobs and social activities. }\end{array}$ \\
\hline & Government digitalization & $\begin{array}{l}\text { Governments adopt digital technologies to improve their public services, leading to higher usage } \\
\text { of digital public services. } \\
\text { Example: Public service offices are being phased out in favor of digital services. }\end{array}$ \\
\hline & Standardization & $\begin{array}{l}\text { Technology standardization requires society to follow along due to compatibility issues } \\
\text { and network effects. } \\
\text { Example: The rollout of RCS in neighboring countries puts pressure on the country to adopt it too. }\end{array}$ \\
\hline & Changing values & $\begin{array}{l}\text { The impact of digital technologies in people's daily life is changing their values, } \\
\text { expectations, and demands. } \\
\text { Example: Customers are becoming more demanding than ever, expecting instant customer } \\
\text { service and service delivery. }\end{array}$ \\
\hline \multirow[t]{4}{*}{ Business } & Benefits & $\begin{array}{l}\text { Businesses offer benefits and more services to their digital customers, causing customers to } \\
\text { adopt these services. } \\
\text { Example: Public transit tickers are often cheaper when paid through a mobile app, leading to } \\
\quad \text { higher usage of the app. }\end{array}$ \\
\hline & Force adoption & $\begin{array}{l}\text { Businesses can abolish traditional services and products in favor of digital ones, forcing } \\
\text { customers to follow. } \\
\text { Example: Some businesses no longer accept non-mobile payments. }\end{array}$ \\
\hline & Customer empowerment & $\begin{array}{l}\text { Consumers are empowered and asked to be part of the product, become co-creators, or engage with the } \\
\text { brand as digital ambassadors. } \\
\text { Example: More service requests can be handled by the customer itself, with businesses actively } \\
\text { promoting them to do so. }\end{array}$ \\
\hline & Changing job profiles & $\begin{array}{l}\text { Job profiles are evolving in line with the DT of the businesses. This results in new jobs and requires } \\
\text { employees to have digital skills training. } \\
\text { Example: Digital skills are actively learned and needed on the work floor. }\end{array}$ \\
\hline
\end{tabular}

major developments in business, society, and digital technologies and by linking these developments together as an integral part of the phenomenon. This way, we attempt to consolidate the literature into a cohesive ensemble. Furthermore, the framework can be modified to specific sectors by changing or adapting the categories on the axes and the unbounded axes allow for extensions with future developments. Thirdly, we want to highlight the importance of the drivers of DT by including these explicitly in the model. We established the various drivers found in the literature in 23 DTI, and we structured these into six categories based on where the driving force operates and where it comes from. Understanding the drivers is of fundamental importance to better understand how DT happens. Research on the drivers of DT is still in initial stages, and this work can provide the conceptual groundwork for further research in this area. Fourthly, this framework advances the discussion in the IS research about the disparities between digitization, digitalization, IT-enabled transformation, and DT (Mertens \& Wiener, 2018). These terms are often used almost interchangeably even though they describe different phenomena (Kane, 2017; Warner \& Wäger, 2019). Our proposed framework can provide a structured approach in clarifying these terms as shown in Fig. 3.
- Digitization means converting analog information and processes to digital ones (Loebbecke \& Picot, 2015b). In other words, it is the usage of IT to change physical tasks or processes into digital variants, which is depicted by the inner white center in the framework.

- Digitalization describes the sociotechnical phenomenon in which digital technologies are increasingly adopted in individuals, companies, and societal contexts (Legner et al., 2017), thereby often turning existing products and services into digital variants (Parviainen et al., 2017). In a business context, this is also referred to as IT- or ISenabled transformation (Gregor, Martin, Fernandez, Stern, \& Vitale, 2006). Creating digital products or services requires a thorough digital backbone consisting of connected digital business processes. On the society side, this changes people's communication with businesses and usage of their products and services. As such, digitalization can be understood as the evolution towards the middle of the framework where there is more integration between digital technologies, products and services, and customer usage.

- DT is generally broader defined as major changes in business, people, and society due to the cumulative impact of increasingly capable digital technologies (Ebert \& Duarte, 2018; Gurbaxani \& Dunkle, 2019; Kane, 2019). In 


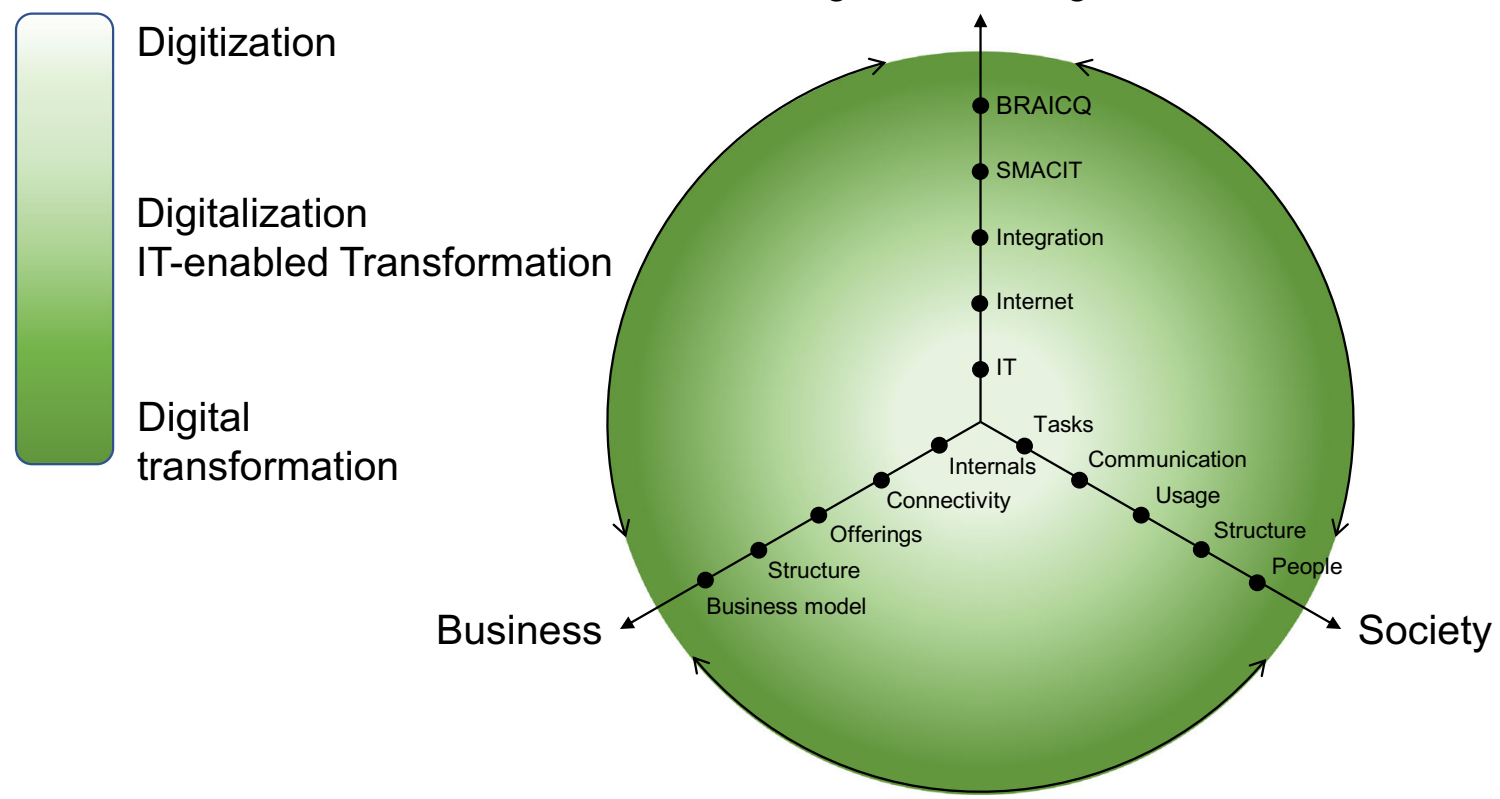

Fig. 3 The evolution of DT

business, this often translates into changes in the company's structure, culture, and business model, or in the industry as a whole such as changing industry borders. In society, DT is linked with changes in the way people work and structure their life, or how their values, beliefs, and expectations alter (Reddy \& Reinartz, 2017; Schwab, 2015). We define DT as the continuously increasing interaction between digital technologies, business, and society, which results in transformational effects and increases the change process' velocity, scope, and impact (Van Veldhoven \& Vanthienen, 2019). Hence, it can be understood as the complete evolution from the center towards the outer edge of the framework.

Not all sectors follow this evolution in these exact steps, complicating the nomenclature. It is well established that different industries and sectors take different transformation paths, and change at a different speed and time (e.g. Bughin et al., 2016). For instance, many retail companies changed their business model into e-commerce, labeled as digitalization at that point, before the arrival of SMACIT technologies. However, it is important to note that the proposed framework sketches the general changes over time, suggesting that when you take the combination of all industries, sectors, and societies, the changes will approximate the framework.

Consequently, we follow Vial's (2019) view that DT is an evolution of IT-enabled transformation or digitalization. Furthermore, we suggest that this, in turn, is an evolution of digitization. The difference between digitalization and DT is not always clear, yet several significant differences are present.
For instance, the unseen velocity, scope, and impact of DT make it distinct from IT-enabled transformations in the past (Schwab, 2015). Furthermore, the rise of network effects and digital ecosystems cause new levels of cooperation and competition (Katsamakas, 2014). Lastly, customers nowadays utilize the same technologies as companies which creates unseen business possibilities (Schallmo et al., 2017), and makes the customer more involved in the DT process compared to IT-enabled transformation (Hagberg, Sundstrom, \& Egels-Zandén, 2016). Although this distinction may seem trivial, the right terminology is, in fact, crucial for the longevity of DT research.

To illustrate how our framework can gain acceptance as a comprehensive model of DT, we consider the banking sector as an example. In banking, we have witnessed massive DT efforts over the past fifty years which follows the evolution this framework specifies. In the 1960s, banks started to digitize their internals using IT, and employees' tasks changed accordingly. Later, the internet drastically changed the connectivity between banks, offices, transactions, and customers. Next, we saw the rise of integration technologies making way for e-banking services and changing the customer usage of bank services. Over the past years, we saw SMACIT technologies resulting in changed connectivity with customers, novel offerings, and structural changes: regional bank offices were closed, main branches are increasingly working in agile teams, and working from home became more popular allowing employees to restructure their daily life. Customers' usage of banking services increasingly changed to mobile, and the practice of going to banks is slowly fading away in society. In recent and coming years, we see the rise of novel business models. For example, N26 is among the first online-only 
banks. Other emerging business models include replacing human cognitive tasks (e.g. investment advice, insurance claims, etc.) with AI-based chatbots, offering house visits, creating value by adding non-bank services to bank apps such as mobility tickets and loyalty cards or experimenting with cryptocurrencies and smart contracts using blockchain. At the same time, people are becoming so accustomed to instant fulfillment that they demand access to instant 24/7 contact, instant money transfers, and the complete service package on mobile. All of this is highly connected; each change impacts all changes in the other dimensions and in turn itself. These changes must not be understood in isolation, but rather as the complex interplay between all changes and DTI across all sectors.

The analysis of the models conducted in this paper indicates that the scope of DT research has slowly widened over the past 10 years to include more aspects and impacts. While the early models were more centered around one-time exercise, the newer ones seem to increasingly highlight the continuous aspect of DT. Our research lens emphasizes this increasing complexity and its impact on the DT process. As digital technologies evolve, they cause changes not only in business but also in society. In doing so, a reactive chain process is activated in which the changing business and society influence each other into digitally transforming. This web of relations and interactions is complex but understanding it may be key to better understand how this change process unfolds.

There is a growing body of literature investigating the impact of the Covid-19 pandemic on the DT efforts of companies. It is generally argued that the pandemic has accelerated DT in many organizations (Soto-Acosta, 2020; Wade \& Shan, 2020). These developments are in line with our framework, where this acceleration can be accredited to the DTI's between business and society. From the side of society, government legislation required companies to cease unnecessary physical touchpoints with customers and to guarantee a safe distance between employees or to let employees work from home. Additionally, employees increasingly demanded a working from home policy even when the workspace followed the safety standards (Papagiannidis, Harris, \& Morton, 2020). In most cases, companies relied on digital solutions to move both the workload and the customer experience to the digital sphere. This required a large effort on short notice, accelerating the DT in these companies. On the other side, businesses both digitally empowered customers and forced adaptation of their digital solutions, accelerating the DT in society. In turn, these changes led to higher demand and adaption of digital technologies such as video conferencing software, online order systems, and online corporate business applications. It will be interesting to see whether these changes will be kept or reversed when the pandemic is under control. This will pose many fruitful research areas, such as why companies reverted to the old ways, or what was missing from the online solutions to be kept permanently.

While businesses can exploit the many opportunities that DT brings forward, their competitive position becomes more fragile as the speed of change is increasing. Together, this brings forward several new business paradigms to deal with the increasing complexity of the business game. Companies must invest in organizational agility without interrupting their core business operations. Often, this consists of being able to sense and seize opportunities quickly (Leonhardt, Haffke, Kranz, \& Benlian, 2017). This two-sided focus is often referred to as organizational ambidexterity (Leonhardt et al., 2017). In turn, this leads to novel characteristics in the business such as a digital strategy which consolidates the IT and business strategy (Sebastian et al., 2017), agile development methods such as Scrum and cross-functional teams (G. C. Kane, Palmer, Phillips, Kiron, et al., 2017), a risk-taking culture (Ebert \& Duarte, 2018), and new executive functions such as a Chief Digital Officer (CDO) to guide the DT efforts (Singh \& Hess, 2017).

Though the opportunities and benefits of a successful DT are plentiful, there are downsides on a global scale too. The digitalization process has been strongly associated with increasing inequality and job loss (EIT digital, 2019). For example, digital platforms are elusive to fair taxation and can harm the local economy, moving money away to the global headquarters. Several authors also warn of the rise of social inequity, fraud, and imbalance of power (Janowski, 2015). On the topic of cyber-security, there are security risks and concerns regarding the increased reliance on digital technologies that can be hacked (Brock \& von Wangenheim, 2019; Vial, 2019). The accustoming to digital technologies has also been linked with changes in social interactions, the loss of empathic ability, the growth of internet addiction, and the desocialization of individuals (Ulez'ko et al., 2019). As a result, a negative reaction of society to DT is possible, halting, or slowing down the DT process. According to Brock and von Wangenheim (2019), for instance, customers will pay a human premium in the future to get human-human contact instead of interacting with computers. It is important to keep track of the different DTI, including the ones that have an adverse effect, and how they influence the transformation of tomorrow.

This work has several limitations. First, due to the sheer number of papers published about DT, we had to narrow our literature search to cited $(>5)$ conference and journal papers in the last 10 years. Analyzing all papers would be a tremendous work but could result in more identified drivers of DT, and potentially other or slightly changed identified shortcomings. Secondly, the constructed framework is theoretical. Although this work is based on the insights from many qualitative case studies or surveys, more empirical research can be beneficial to validate our proposed framework. 


\section{Research agenda}

This holistic and combining view provides a prolific and unique lens to study DT. Using this lens, researchers gain the opportunity to further enhance their understanding of DT and can gain novel insights about the complex change process and the way it unfolds. Many research avenues that are still being investigated in DT research can be approached from this viewpoint, such as why certain business dimensions are chosen to be transformed before others, the long-term impact of DT (Henriette et al., 2015), how radical digital innovations are created (Skog et al., 2018), how novel infrastructures emerge and gain legitimacy (Hinings et al., 2018), what the effects of increasing digitalization on different sectors are (Cziesla, 2014), how digital innovation triggers the dynamic processes that may generate digital disruption (Skog et al., 2018), and what the role of the individual is in this phenomenon (Matt et al., 2019). Research into the DTI and to what extent these interactions shape the transformation can provide answers to these questions and can be an important pillar of understanding IT diffusion (Matt et al., 2019).

The framework introduced in this paper offers an overview of the different changes and drivers of DT. However, the DTI in this paper are not comprehensive and can be further expanded. More empirical research must be done to validate the drivers, whether the DTI accelerate this change process, explore the under-researched DTI, and investigate the strength of the feedback loops that are described in this paper. Additionally, future research can investigate whether the enablers for change in a company primarily come from technology or society and how much each change aspect affects this pressure. The categories can also be extended to include other aspects or sector-specific versions of the DT framework can be created. Another research avenue is investigating how maturity models can be combined with the DT framework to create maturity stages in each category in each dimension.

More effort must be done to utilize the right terminologies in DT research. This is important to keep the research field relevant and focused. The DT framework can serve as a cornerstone of this debate. We hope that the DT research community will also widen its research focus to investigate the larger changes of DT such as the shift from customercentricity to the everyone-to-everyone economy (Berman \& Marshall, 2014), self-servitization, traditional industry borders that are fading, digital ecosystems, shifting business models, and so forth. A substantial portion of the DT literature is still limited to the implementation of a certain technology in a company, which falls under digitalization.

In addition, further research can investigate the role and effect of society and individuals in the DT process (Matt et al., 2019). While many papers touch upon the role of customers' demands, little is known about the full range of effects society has on business transformation. Therefore, it is important to bring together different research streams. The DTI provide a good starting point for future work in this area. We believe DT has the academic interest and power to bring together social and IS research streams to investigate the role of society in DT.

Practitioners and researchers can be informed through our work about the meaning and extent of DT. Our work suggests that DT is a complex change process steered by the increasing interaction of technology, business, and society. The proposed DT framework can aid with interpretation and understanding of how these changes interact with each other and can be used as a tool for brainstorming sessions. For instance, when thinking about how a new business model might be impacted by DT, modeling it on the DT framework can provide novel insights into its strengths, weaknesses, opportunities, and threats. This calls for more empirical research into the framework.

\section{Conclusion}

In this paper, we conducted a developmental review of 41 DT models which identified four research opportunities. We contribute to the DT research by classifying our insights around a novel, comprehensive framework that includes the major changes in business, society, and technology. In addition, we highlight the complexity of the process and categorize the drivers of DT in 23 DTI and 6 categories. Our study provides a novel lens through which DT can be studied. It can help to better understand how the changes unfold and how these changes influence each other. By connecting both the business and society, we hope to bring together these research streams to better understand the role of society. Ultimately, this work can be the first step towards a unified understanding of DT.

\section{References}

Andal-ancion, A., Cartwright, P. A., \& Yip, G. S. (2003). The digital transformation of traditional businesses. MIT Sloan Management Review, 44(4), 34-41.

Austin, R. D., \& Upton, D. M. (2016). Leading in the age of supertransparency. MIT Sloan Management Review, 57(2), 25-32. https://doi.org/10.1109/emr.2016.7559059.

Baden-Fuller, C., \& Haefliger, S. (2013). Business models and technological innovation. Long Range Planning, 46(6), 419-426. https:// doi.org/10.1016/j.lrp.2013.08.023.

Berghaus, S., \& Back, A. (2016). Stages in digital business transformation: Results of an empirical maturity study. Proceedings of the Mediterranean Conference on Information Systems (MCIS), 117.

Berman, \& Marshall, A. (2014). The next digital transformation: From an individual-centered to an everyone-to-everyone economy. Strategy 
and Leadership, 42(5), 9-17. https://doi.org/10.1108/SL-07-20140048.

Berman, S. J. (2012). Digital transformation: Opportunities to create new business models. Strategy and Leadership, 40(2), 16-24. https://doi. org/10.1108/10878571211209314.

Besson, P., \& Rowe, F. (2012). Strategizing information systems-enabled organizational transformation: A transdisciplinary review and new directions. Journal of Strategic Information Systems, 21, 103-124. https://doi.org/10.1016/j.jsis.2012.05.001

Bharadwaj, A. S. (2000). A resource-based perspective on information technology capability and firm performance: An empirical investigation. MIS Quarterly, 24(1), 169-196. https://doi.org/10.2307/ 3250983.

Brock, J. K.-U., \& von Wangenheim, F. (2019). Demystifying AI: What digital transformation leaders can teach you about realistic artificial intelligence. California Management Review, 61, 110-134. https:// doi.org/10.1177/1536504219865226.

Bughin, J., Hazan, E., Labaye, E., Manyika, J., Dahlström, P., Ramaswamy, S., \& Cochin de Billy, C. (2016). Digital Europe: pushing the frontier, capturing the benefits. Mckinsey Global Institute.

Catlin, T., Scanlan, J., \& Willmott, P. (2015). Raising your digital quotient. McKinsey Quarterly, (June), 1-13. https://doi.org/10.1088/ 0004-637X/752/2/97.

Chanias, S. (2017). Mastering digital transformation: the path of a financial services provider towards a digital transformation strategy. Proceedings of the 25th European Conference on Information Systems (ECIS), 17.

Christensen, C. M., Raynor, M. E., \& McDonald, R. (2015). What is disruptive innovation. Harvard Business Review, Dec., 44-53.

Colli, M., Madsen, O., Berger, U., Møller, C., Wæhrens, B. V., \& Bockholt, M. (2018). Contextualizing the outcome of a maturity assessment for industry 4.0. IFAC-PapersOnLine, 51(11), 13471352. https://doi.org/10.1016/j.ifacol.2018.08.343.

Cziesla, T. (2014). A literature review on digital transformation in the financial service industry. Proceedings of the 27th Bled EConference, 25-36.

Ebert, C., \& Duarte, C. H. C. (2018). Digital transformation. IEEE Software, 35(4), 16-21. https://doi.org/10.1109/MS.2018.2801537.

EIT digital. (2019). Digital Transformation of European Industry - a Policy Perspective - Summary. Www.Eitdigital.Eu, 20. Retrieved from https://www.eitdigital.eu/fileadmin/files/2019/report/full/ Digital-Transformation-of-European-Industry-Full-Report.pdf.

Fagerstrom, A., Ghinea, G., \& Sydnes, L. (2010). Understanding the impact of online reviews on customer choice: A probability discounting approach. Psychology \& Marketing, 33(2), 125-134. https://doi.org/10.1002/mar.20859.

Faro, B., Abedin, B., \& Kozanoglu, D. C. (2019). Continuous transformation of public-sector Organisations in the digital era. Twenty-Fifth Americas Conference on Information Systems (AMCIS), 1-7.

Frank, A. G., Mendes, G. H. S., Ayala, N. F., \& Ghezzi, A. (2019). Servitization and industry 4.0 convergence in the digital transformation of product firms: A business model innovation perspective. Technological Forecasting and Social Change, 141, 341-351. https://doi.org/10.1016/j.techfore.2019.01.014.

Gerbert, P., Gauger, C., \& Steinhäuser, S. (2015). The double game of digital strategy. Bcg Perspectives, 1-6. Retrieved from http://imagesrc.bcg.com/Images/BCG-The-Double-Game-of-Digital-StrategyOct-2015 tcm9-88402.pdf.

Goerzig, D., \& Bauernhansl, T. (2018). Enterprise architectures for the digital transformation in small and medium-sized enterprises, Procedia CIRP, 67, 540-545. https://doi.org/10.1016/j.procir. 2017.12.257.

Gray, P., Asper, G., El Sawy, O. A., \& Thordarson, M. (2013). Realizing strategic value through center-edge digital transformation in consumer-centric industries. MIS Quarterly, 12(1), 1-17. https:// doi.org/10.1108/02635570910926564.

Gregor, S., Martin, M., Fernandez, W., Stern, S., \& Vitale, M. (2006). The transformational dimension in the realization of business value from information technology. Journal of Strategic Information Systems, 15, 249-270. https://doi.org/10.1016/j.jsis.2006.04.001.

Guest, M. (2014). Building your digital DNA: Lessons from digital leaders contents the digital organisation. Deloitte, 51. Retrieved from https://www2.deloitte.com/content/dam/Deloitte/global/ Documents/Technology/gx-technology-building-your-digitaldna.pdf

Gurbaxani, V., \& Dunkle, D. (2019). Gearing up for successful digital transformation. MIS Quarterly Executive, 18(3), 209-220. https:// doi.org/10.17705/2msqe.00017.

Haffke, I., Kalgovas, B., \& Benlian, A. (2016). The role of the CIO and the CDO in an Organization's digital transformation. ICIS 2016 Proceedings, 1-20.

Hagberg, J., Sundstrom, M., \& Egels-Zandén, N. (2016). The digitalization of retailing: An exploratory framework. International Journal of Retail and Distribution Management, 44(7), 694-712. https://doi. org/10.1108/IJRDM-09-2015-0140.

Hall, B. H., \& Khan, B. (2003). Adoption of new technology. National Bureau of Economic Research (NBER) Working Paper Series. https://doi.org/10.3386/w9730.

Hartl, E., \& Hess, T. (2017). The role of cultural values for digital transformation: Insights from a Delphi study. Proceedings of the $23 \mathrm{rd}$ Americas Conference on Information Systems (AMCIS 2017), Boston, USA.

He, Q., Meadows, M., Angwin, D., Gomes, E., \& Child, J. (2020). Strategic Alliance research in the era of digital transformation: Perspectives on future research. British Journal of Management, 00, 1-29. https://doi.org/10.1111/1467-8551.12406.

Heavin, C., \& Power, D. J. (2018). Challenges for digital transformationtowards a conceptual decision support guide for managers. Journal of Decision Systems, 27, 38-45. https://doi.org/10.1080/12460125. 2018.1468697.

Henriette, E., Feki, M., \& Boughzala, I. (2015). The shape of digital transformation: A systematic literature review. Proceedings of the Mediterranean Conference on Information Systems (MCIS), 431-443.

Hinings, B., Gegenhuber, T., \& Greenwood, R. (2018). Digital innovation and transformation: An institutional perspective. Information and Organization, 28(1), 52-61. https://doi.org/10.1016/j. infoandorg.2018.02.004

Horlach, B., Drews, P., \& Schirmer, I. (2016). Bimodal IT : Business-IT alignment in the age of digital transformation. Multikonferenz Wirtschaftsinformatik (MKWI), 1417-1428.

Ifenthaler, D., \& Egloffstein, M. (2020). Development and implementation of a maturity model of digital transformation. TechTrends, 64(2), 302-309. https://doi.org/10.1007/s11528-019-00457-4.

Issa, A., Hatiboglu, B., Bildstein, A., \& Bauernhansl, T. (2018). Industrie 4.0 roadmap: Framework for digital transformation based on the concepts of capability maturity and alignment. Procedia CIRP, 72, 973-978. https://doi.org/10.1016/j.procir.2018.03.151.

Ivanov, I. I. (2019). Chasing the crowd: Digital transformations and digital driven system design paradigm. In: Shishkov, B. (Eds.). Business Modeling and Software Design. BMSD 2019. Lecture Notes in Business Information Processing, vol 356, (pp. 64-80). Springer International Publishing. https://doi.org/10.1007/ 978-3-030-24854-3_5

Janowski, T. (2015). Digital government evolution: From transformation to contextualization. Government Information Quarterly, 32(3), 221-236. https://doi.org/10.1016/j.giq.2015.07.001.

Kane. (2017). Digital Maturity, Not Digital Transformation. MIT Sloan Management Review. 
Kane, G. (2019). The technology fallacy: People are the real key to digital transformation. Research Technology Management, 62(6), 44- 49. https://doi.org/10.1080/08956308.2019.1661079.

Kane, G. C., Palmer, D., Philips, A. N., Kiron, D., \& Buckley, N. (2015). Strategy, not technology, drives digital transformation. MIT Sloan Management Review and Deloitte University Press.

Kane, G. C., Palmer, D., Phillips, A. N., \& Kiron, D. (2017a). Winning the digital war for talent. MIT Sloan Management Review, 58(2), $17-19$.

Kane, G. C., Palmer, D., Phillips, A. N., Kiron, D., \& Buckly, N. (2017b). Achieving digital maturity. MIT Sloan Management Review, 59(1), $1-29$.

Katsamakas, E. (2014). Value network competition and information technology. Human Systems Management, 33(1-2), 7-17. https:// doi.org/10.3233/HSM-140810

Kaufman, I., \& Horton, C. (2014). Digital transformation: Leveraging digital technology with Core values to achieve sustainable business goals. The European Financial Review, 63-67.

Kotarba, M. (2018). Digital transformation of business models. Foundations of Management, 10(1), 123-142. https://doi.org/10. 2478/fman-2018-0011

Kotter, J. P. (1995). Leading change: Why transformation efforts fail. Harvard Business Review, 12, 9. https://doi.org/10.1016/00291021(73)90084-4.

KPMG International. (2016). Now or Never: 2016 Global CEO Outlook. Retrieved from https://images.forbes.com/forbesinsights/ StudyPDFs/KPMG-Global_CEO_Outlook-REPORT.pdf.

Kumar Basu, K. (2015). The Leader's role in managing change: Five cases of technology-enabled business transformation. Global Business and Organizational Excellence, 34(3), 28-42. https://doi. org/10.1002/joe.

Legner, C., Eymann, T., Hess, T., Matt, C., Böhmann, T., Drews, P., Mädche, A., Urbach, N., \& Ahlemann, F. (2017). Digitalization: Opportunity and challenge for the business and information systems engineering community. Business \& Information Systems Engineering, 59(4), 301-308. https://doi.org/10.1007/s12599-0170484-2.

Leonhardt, D., Haffke, I., Kranz, J., \& Benlian, A. (2017). Reinventing the IT function: The role of IT agility and IT ambidexterity in supporting digital business transformation. Proceedings of the 25th European Conference on Information Systems (ECIS), Guimarães, Portugal, 968-984.

Lismont, J., Vanthienen, J., Baesens, B., \& Lemahieu, W. (2017). Defining analytics maturity indicators: A survey approach. International Journal of Information Management, 37(3), 114 124. https://doi.org/10.1016/j.ijinfomgt.2016.12.003.

Loebbecke, C., \& Picot, A. (2015a). Reflections on societal and business model transformation arising from digitization and big data analytics: A research agenda. Journal of Strategic Information Systems, 24(3), 149-157. https://doi.org/10.1016/j.jsis.2015.08.002.

Loebbecke, C., \& Picot, A. (2015b). Reflections on societal and business model transformation arising from digitization and big data analytics: A research agenda. Journal of Strategic Information Systems, 24(3), 149-157. https://doi.org/10.1016/j.jsis.2015.08.002.

Lucas, H. C., Agarwal, R., Clemons, E. K., El Sawy, O. A., \& Weber, B. (2013). Impactful research on transformational information technology: An opportunity to inform new audiences. MIS Quarterly, 37(2), 371-382.

Matt, C., Hess, T., \& Benlian, A. (2015). Digital transformation strategies. Business and Information Systems Engineering, 57(5), 339343. https://doi.org/10.1007/s12599-015-0401-5.

Matt, C., Trenz, M., Cheung, C. M. K., \& Turel, O. (2019). The digitization of the individual: Conceptual foundations and opportunities for research. Electronic Markets, 29(3), 315-322. https://doi.org/10. 1007/s12525-019-00348-9.
Matzler, K., Friedrich von den Eichen, S., Anschober, M., \& Kohler, T. (2018). The crusade of digital disruption. Journal of Business Strategy, 39(6), 13-20. https://doi.org/10.1108/JBS-12-2017-0187.

Mergel, I., Edelmann, N., \& Haug, N. (2019). Defining digital transformation: Results from expert interviews. Government Information Quarterly, (June), 1-16. https://doi.org/10.1016/j.giq.2019.06.002.

Mertens, P., \& Wiener, M. (2018). Riding the Digitalization Wave: Toward a sustainable nomenclature in Wirtschaftsinformatik. A comment on Riedl et al. (2017). Business and Information Systems Engineering, 60(4), 367-372. https://doi.org/10.1007/s12599-0180545-1.

Misuraca, G., Pasi, G., \& Viscusi, G. (2018). Social innovation and resilience: Exploring the dynamics and impacts on the digital transformation of governance \& society. Proceedings of the 11th International Conference on Theory and Practice of Electronic Governance (ICEGOV), 91-100. https://doi.org/10.1145/3209415. 3209488 .

Morgan, R. E., \& Page, K. (2008). Managing business transformation to deliver strategic agility. Strategic Change, 17, 155-168. https://doi. org $/ 10.1002 /$ jsc. 823

Nwaiwu, F. (2018). Review and comparison of conceptual frameworks on digital business transformation. Journal of Competitiveness, 10(3), 86-100. https://doi.org/10.7441/joc.2018.03.06 .

Oestreicher-Singer, G., \& Zalmanson, L. (2013). Content or community? A digital business strategy for content. Management Information Systems Quarterly, 37(2), 591-616.

Osterwalder, A., \& Pigneur, Y. (2010). Business Model Generation. Wiley., 30, 4015-4023. https://doi.org/10.1523/JNEUROSCI. 0307-10.2010.

Papagiannidis, S., Harris, J., \& Morton, D. (2020). WHO led the digital transformation of your company? A reflection of IT related challenges during the pandemic. International Journal of Information Management, 55, 102166. https://doi.org/10.1016/j.ijinfomgt.2020. 102166.

Parviainen, P., Tihinen, M., Kääriäinen, J., \& Teppola, S. (2017). Tackling the digitalization challenge: How to benefit from digitalization in practice. International Journal of Information Systems and Project Management, 5(1), 63-77. https://doi.org/10.12821/ ijispm050104.

Patel, K., \& McCarthy, M. P. (2000). Digital transformation: The essentials of E-business leadership. McGraw-Hill Professional.

Pihir, I., Tomičić-Pupek, K., \& Tomičić Furjan, M. (2019). Digital transformation playground - literature review and framework of concepts. Journal of Information and Organization Sciences (JIOS), 43(1), 33-48. https://doi.org/10.31341/jios.43.1.3

Rachinger, M., Rauter, R., Müller, C., Vorraber, W., \& Schirgi, E. (2018). Digitalization and its influence on business model innovation. Journal of Manufacturing Technology Management., 30, 11431160. https://doi.org/10.1108/JMTM-01-2018-0020.

Rautenbach, W. J., De Kock, I., \& Jooste, J. L. (2019). The development of a conceptual model for enabling a value-adding digital transformation : A conceptual model that aids organisations in the digital transformation process. Proceedings of the International Conference on Engineering, Technology and Innovation (ICE/ ITMC) Valbonne Sophia-Antipolis, France, 1-10. https://doi.org/ 10.1109/ICE.2019.8792675.

Reddy, S. K., \& Reinartz, W. (2017). Digital transformation and value creation: Sea change ahead. GfK Marketing Intelligence Review, 9(1), 10-17. https://doi.org/10.1515/gfkmir-2017-0002.

Reis, J., Amorim, M., Melão, N., \& Matos, P. (2018). Digital Transformation: A Literature Review and Guidelines for Future Research. In: Rocha Á., Adeli H., Reis L.P., Costanzo S. (Eds.) Trends and Advances in Information Systems and Technologies. WorldCIST'18, (vol. 745). Springer, Cham. https://doi.org/10. 1007/978-3-319-77703-0_41. 
Riasanow, T., Setzke, D. S., \& Böhm, M. (2019). Clarifying the notion of digital transformation : A Transdisciplinary review of literature. Journal of Competences, Strategy \& Management, 10(April), 531.https://doi.org/10.2139/ssrn.3072318.

Risselada, H., Verhoef, P. C., \& Bijmolt, T. H. A. (2013). Dynamic effects of social influence and direct marketing on the adoption of high-technology products. Journal of Marketing, 78(2), 52-68. https://doi.org/10.1509/jm.11.0592.

Rogers, E. M. (2010). Diffusion of innovations. The Free Press, A Division of Simon and Schuster.

Sanchez, M. A. (2017). Framework to assess organizational readiness for digital transformation. Dimensión Empresarial, 15(2), 27-40. https://doi.org/10.15665/RDE.V15I2.976.

SAP Insight. (2017). 4 Ways Leaders Set Themselves Apart. Retrieved from: https://insights.sap.com/sap-digital-transformation-executivestudy-4-ways-leaders-set-themselves-apart/.

Schallmo, D., \& Williams, C. (2018). Digital transformation now! Guiding the Successful Digitalization of Your Business Model. IEEE Software, 35, 16-21. https://doi.org/10.1109/MS.2018. 2801537.

Schallmo, D., Williams, C. A., \& Boardman, L. (2017). Digital transformation of business models - Best practice, enablers, and roadmap. International Journal of Innovation Management, 21(08), 17. https://doi.org/10.1142/s136391961740014x.

Schuchmann, D., \& Seufert, S. (2015). Corporate learning in times of digital transformation: A conceptual framework and service portfolio for the learning function in banking Organisations. International Journal of Advanced Corporate Learning (IJAC), 8(1), 31-39. https://doi.org/10.3991/ijac.v8i1.4440.

Schwab, K. (2015). The fourth industrial revolution. Snapshot, 10, 1-9. https://doi.org/10.1038/nnano.2015.286.

Schwartz, E. I. (2001). Digital Darwinism: 7 breakthrough business strategies for surviving in the cutthroat web economy. Crown Business.

Schwarzmüller, T., Brosi, P., Duman, D., \& Welpe, I. M. (2018). How does the digital transformation affect organizations? Key themes of change in work design and leadership. Management Revue, 29(2), 114-138. https://doi.org/10.5771/0935-9915-2018-2-114.

Sebastian, I. M., Ross, J. W., Beath, C., Mocker, M., Moloney, K. G., \& Fonstad, N. O. (2017). How big old companies navigate digital transformation. MIS Quarterly Executive, 16(3), 197-213. https:// doi.org/10.1017/S0021859600058731.

Shwayder, M. (2019). Why have Americans turned a cold shoulder to messaging giant WhatsApp?. Digital Trends. Retrieved from https:// www.digitaltrends.com/social-media/why-dont-americans-usewhatsapp/.

Singh, A., \& Hess, T. (2017). How chief digital officers promote the digital transformation of their companies. MIS Quarterly Executive, 16(1), 1-17. http://search.ebscohost.com/login.aspx? direct $=$ true $\& \mathrm{db}=\mathrm{bth} \& \mathrm{AN}=121491404 \&$ site $=$ ehost-live.

Skog, D. A., Wimelius, H., \& Sandberg, J. (2018). Digital Disruption. Business \& Information Systems Engineering, 60(5), 431-437. https://doi.org/10.1007/s12599-018-0550-4.

Solis, B. (2015). The six stages of digital transformation maturity. Altimeter Group, 1-29.

Soto-Acosta, P. (2020). COVID-19 pandemic: Shifting digital transformation to a high-speed gear. Information Systems Management, 37(4), 260-266. https://doi.org/10.1080/10580530.2020.1814461.

Stolterman, E., \& Fors, A. C. (2004). Information Technology and the Good Life. In: Kaplan B., Truex D.P., Wastell D., Wood-Harper A.T., DeGross J.I. (Eds.) Information Systems Research. IFIP International Federation for Information Processing (Vol. 143). Springer, Boston, MA. https://doi.org/10.1007/1-4020-8095-6 45.
Subramaniam, M., Iyer, B., \& Venkatraman, V. (2019). Competing in digital ecosystems. Business Horizons, 62(1), 83-94. https://doi.org/ 10.1016/j.bushor.2018.08.013.

Templier, M., \& Paré, G. (2015). A framework for guiding and evaluating literature reviews. Communications of the Association for Information Systems, 37, 112-137. https://doi.org/10.17705/1cais. 03706.

Ulez'ko, A., Demidov, P., \& Tolstykh, A. (2019). The effects of the digital transformation. Proceedings of the International Scientific and Practical Conference "Digital agriculture - development strategy” (ISPC 2019), 125-129. Atlantis Press. https://doi.org/10.2991/ ispc-19.2019.28.

Valdez-De-Leon, O. (2016). A digital maturity model for telecommunications service providers. Technology Innovation. Management Review, 6(8), 19-32. https://doi.org/10.22215/timreview/1008.

Van Veldhoven, Z., \& Vanthienen, J. (2019). Designing a Comprehensive Understanding of Digital Transformation and its Impact. Proceedings of 32nd Bled eConference: Humanizing Technology for a Sustainable Society, 745-763. https://doi.org/10. 18690/978-961-286-280-0.

Venkatraman, N. (1994). It-enabled business transformation - from automation to business scope redefinition. Sloan Management Review, 35(2), 73-87. https://doi.org/10.1002/qua.560360829.

Verhoef, P. C., Broekhuizen, T., Bart, Y., Bhattacharya, A., Qi Dong, J., Fabian, N., \& Haenlein, M. (2019). Digital transformation: A multidisciplinary reflection and research agenda. Journal of Business Research., 122, 889-901. https://doi.org/10.1016/j.jbusres.2019. 09.022 .

Vial, G. (2019). Understanding digital transformation: A review and a research agenda. Journal of Strategic Information Systems, 28(2), 1-27. https://doi.org/10.1016/j.jsis.2019.01.003.

von Leipzig, T., Gamp, M., Manz, D., Schöttle, K., Ohlhausen, P., Oosthuizen, G., Palm, D., \& von Leipzig, K. (2017). Initialising customer-orientated digital transformation in enterprises. Procedia Manufacturing, 8, 517-524. https://doi.org/10.1016/j.promfg.2017. 02.066 .

Wade, M., \& Shan, J. (2020). Covid-19 has accelerated digital transformation, but may have made it harder not easier. MIS Quarterly Executive, 19(3), 213-220. https://doi.org/10.17705/2msqe.00034.

Warner, K. S. R., \& Wäger, M. (2019). Building dynamic capabilities for digital transformation: An ongoing process of strategic renewal. Long Range Planning, 52(3), 326-349. https://doi.org/10.1016/j. lrp.2018.12.001.

Webster, J., \& Watson, R. T. (2002). Analyzing the past to prepare for the future: Writing a literature review. MIS Quarterly, 26(2), xiii-xxiii.

Westerman, G., Bonnet, D., \& McAfee, A. (2012). The digital capabilities your company needs. MIT Sloan Management Review. Retrieved from http://sloanreview.mit.edu/article/the-digitalcapabilities-your-company-needs/.

Westerman, G., Calméjane, C., Bonnet, D., Ferraris, P., \& McAfee, A. (2011). Digital transformation: A road-map for billion-Dollar organizations. Capgemini Consulting \& MIT Sloan Management.

Forum, W. E. (2018). Makerspaces and Local Economic Development. The future of jobs report, 31, 2018-2173. https://doi.org/10.1177/ 0891242417690604.

Ziyadin S., Suieubayeva S., Utegenova A. (2020) Digital Transformation in Business. In: Ashmarina S., Vochozka M., Mantulenko V. (Eds.) Digital Age: Chances, Challenges and Future. ISCDTE 2019. Lecture Notes in Networks and Systems, (Vol. 84). Springer, Cham. https://doi.org/10.1007/978-3-030-27015-5_49.

Publisher's note Springer Nature remains neutral with regard to jurisdictional claims in published maps and institutional affiliations. 